\title{
Solasodine Glycosides: A Topical Therapy for Actinic Keratosis. A Single-Blind, Randomized, Placebo-Controlled, Parallel Group Study with Curaderm
}

\author{
Bill E. Cham \\ Australasian Institute of Medical Research, Brisbane, Australia. \\ Email: bill.cham@gmail.com \\ Received January $31^{\text {st }}, 2013$; revised March $1^{\text {st }}, 2013$; accepted March $8^{\text {th }}, 2013$ \\ Copyright (C) 2013 Bill E. Cham. This is an open access article distributed under the Creative Commons Attribution License, which \\ permits unrestricted use, distribution, and reproduction in any medium, provided the original work is properly cited.
}

\begin{abstract}
Background: Untreated actinic keratosis can advance to squamous cell carcinoma, which in turn is associated with a risk of metastasis. Current treatments for actinic keratosis have many shortcomings. This communication describes the efficacy and safety of a topical cream therapy, Curaderm ${ }^{\mathrm{BEC} 5}$, containing solasodine glycosides $(0.005 \%)$ for actinic keratosis. Methods: Randomly assigned patients with actinic keratosis on the face, trunk or extremities received solasodine glycosides cream (Curaderm ${ }^{\mathrm{BEC} 5}$ ) or placebo (vehicle) that was self-applied to the lesions and covered with an occlusive dressing (micropore) twice daily for 3 consecutive days. Complete clearance and local reactions were assessed at 56 days with follow-up periods of 6 months and 1 year. Results: The rate of complete clearance at day 56 was higher with solasodine glycosides than with placebo $(92 \%$ vs. $38 \%, \mathrm{P}<0.001)$. The absolute success rates after 1 year follow-up were $82 \%$ for solasodine glycosides and $18 \%$ for placebo. No differences in local reactions were obtained when solasodine glycosides and placebo were compared. Local reactions in both groups peaked at days 2 and 3 with local pain as the major event. The pain associated with treatments lasted approximately 10 minutes after application of solasodine glycosides and placebo. Complete reepithelialization occurred two weeks after treatment. Adverse events were generally mild to moderate in intensity and resolved without sequelae. Conclusions: Solasodine glycosides cream applied topically twice daily with a dressing for 3 days is effective for the treatment of actinic keratoses.
\end{abstract}

Keywords: Solasodine Glycosides; Solamargine; Solasonine; Actinic Keratosis; Apoptosis; Skin Cancer; Clinical Trial; Curaderm $^{\mathrm{BEC5}}$

\section{Introduction}

Actinic keratosis (AK) also known as solar keratosis (SK) and senile keratosis is a premalignant lesion of thick, scaly or crusty patch of skin. It is associated with those who are frequently exposed to the sun and is more common in fair-skinned people, and it is usually accompanied by solar damage [1]. Actinic keratosis is very common, affecting half of the global population, and prevalence may vary with geographical location and age. Immunosuppressive drugs used in organ transplant patients increase the development of actinic keratosis more than 250 times which may lead to skin cancer. Actinic keratosis is considered as potentially pre-cancerous, since up to twenty percent of untreated lesions may progress to squamous cell carcinoma [2].
The treatments of actinic keratosis include different forms of surgery, curettage and cautery, cryotherapy, chemotherapy $(5 \mathrm{FU})$, radiotherapy, photodynamic therapy, diclofenac and imiquimod. Choosing the correct treatment regimen and being aware of its limitations can reduce the burden of disease and help to prevent squamous cell carcinoma. Potential scarring, low success rates, high recurrence rates, long duration of treatment and prolonged local reactions are major drawbacks with current treatments [3].

The glycoalkaloids solamargine and solasonine singly or in combination are known to be good antineoplastic biological therapeutic agents [4-36]. These chemical compounds occur in plants of the Solanaceae family such as S. linnaeanum (devil's apple) and S. melongena (egg- 
plant) $[37,38]$.

The antineoplastic mode of action of these solasodine glycosides has been elucidated. They are regarded as biological therapies, also known as targeted therapies that target the differences between cancer cells and normal cells. It appears that malignant cells have specific rhamnose receptors that bind to the rhamnose sugar moiety of the solasodine glycosides [6,27,31]. The solasodine glycosides are internalized by receptor-mediated endocytosis through "coated pit endocytosis". Gradual transformation of receptorsomes to endosomes results in the formation of lysosomes. The solasodine glycosides then trigger extrinsic and intrinsic apoptotic pathways in the cancer cells by up-regulating the expressions of external death receptors, such as tumour necrosis factor receptor 1 (TNFR-1), Fas receptor, TNFR-1-associated death domain and Fas-associated death domain. The solasodine glycosides enhance the intrinsic ratio of $\mathrm{Bax}$ to $\mathrm{Bcl}-2$ by up-regulating Bax and down-regulating Bcl-2 and Bcl$\mathrm{xL}$ expressions. These effects result in activation of Caspase $-8,-9$ and -3 in cancer cells, indicating that extrinsic and intrinsic apoptotic pathways in cancer cells $[8,22,23,27-31,38,39]$ are triggered by the solasodine glycosides.

Normal, non malignant cells do not possess the rhamnose binding protein receptor and are therefore not affected by therapeutic doses of the solasodine glycosides $[4,5,27,29]$.

BEC is a standardized mixture of the solamargine (33\%), solasonine (33\%) and di- and monoglycosides (34\%). All the glycosides contain the same aglycone solasodine [4, 20,21,29,32-36]. Figure 1 shows the chemical structures of solamargine and solasonine.

Cream formulations containing the BEC solasodine glycosides are effective topical treatments for human malignant skin cancers [4,20-22,29,32-36]. Phases I and II clinical trials have established safety and efficacy of various forms of topical formulations [4,20,29,32-36,38, 39]. Subsequently with Phase III clinical studies it was shown that very low concentrations of BEC were required to eliminate the malignant skin cancers basal cell and squamous cell carcinomas $[4,20,21,29,32,34-36,38]$. The concentrations of BEC to treat the malignant lesions were similar to the effective concentrations of BEC with a wide variety of tumour cells in cell culture studies [5, 6,8-13,16,17,19-21,23,27-32,34-36].

However, with the studies of the very low concentrations of BEC in the topical cream, it was necessary to optimize the bioavailability of the BEC to the cancer cells. This was obtained by adding relatively high concentrations of the keratolytic agents salicylic acid and urea to the formulation.

In 1987 it was reported that $10 \%$ BEC in a topical cream formulation obtained regression in 23 of 23 kera-

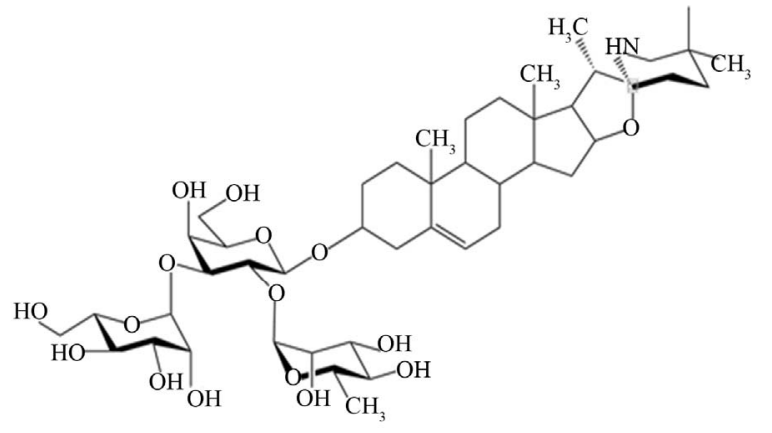

Solasonine

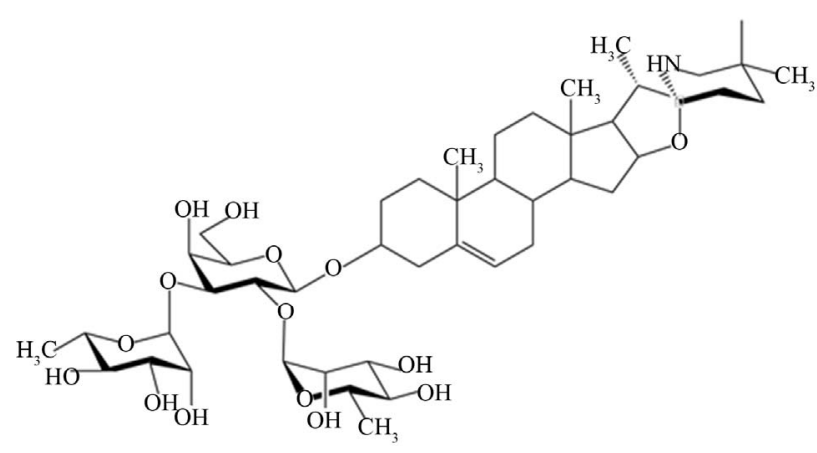

Solamargine

Figure 1. Chemical structures of solasonine and solamargine.

totic lesions in patients [33]. In an open study in 1991 clinical and histological observations indicated that $56 \mathrm{ke}-$ ratoses were cleared with very low concentrations $(0.005 \%)$ of $\mathrm{BEC}$ in a cream formulation Curaderm ${ }^{\mathrm{BEC} 5}$ [32]. No adverse effects in the liver, kidneys or haematopoietic system with Curaderm ${ }^{\mathrm{BEC} 5}$ were reported [32]. In 1991 Curaderm ${ }^{\mathrm{BEC} 5}$ was licensed in Australia by the TGA for the indication of solar keratosis.

In all previous studies the treatment periods for $\mathrm{AK}$ ranged from 1 - 3 weeks $[32,33]$.

No studies are available to determine the optimal time period for Curaderm ${ }^{\mathrm{BEC} 5}$ treatment and the effect of the Curaderm ${ }^{\mathrm{BEC} 5}$ placebo on $\mathrm{AK}$.

This communication describes a single-blind, placebo-controlled clinical trial using Curaderm ${ }^{\mathrm{BEC} 5}$ topically for 3 days for the treatment of clinically diagnosed AK.

\section{Materials and Methods}

Study design-This trial was a single-blind, randomized, vehicle-controlled clinical study. The cream formulation Curaderm ${ }^{\mathrm{BEC} 5}$ is available to patients in several countries. 
Curaderm ${ }^{\mathrm{BEC} 5}$ was used as the active test medication and vehicle (Curaderm ${ }^{\mathrm{BEC} 5}$ cream without the BEC solasodine glycosides) was used as the placebo control. AK included in the study was clinically diagnosed.

Assignment to treatment groups-The active medication Curaderm ${ }^{\mathrm{BEC} 5}$ and vehicle cream were randomly assigned in advance at a ratio 1:1. The patients were blinded to treatment.

Method of application-The cream was applied as a thin layer (approximately $50-100$ microliters) to the lesion every $12 \mathrm{~h}$ under occlusive dressing (micropore paper tape) for 3 days. Both the active Curaderm ${ }^{\mathrm{BEC} 5}$ cream and the vehicle produced local irritation and erosion of the lesion. Hence, there was no clinical bias of the patient.

Study medication and evaluation-The vehicle was composed of $10 \%$ salicylic acid and 5\% urea in a stabilized cetomacrogol base. Curaderm ${ }^{\mathrm{BEC} 5}$, on the other hand, was composed of the vehicle $+0.005 \%$ solasodine glycosides (BEC) [32,34,36].

Patient inclusion criteria-Patients aged 42 years and over consisting of 40 males (mean age 66 years) and 38 females (mean age 68 years) with clinically diagnosed AK were included in this study. The patients had Fitzpatrick skin types I, II and III (Table 1). All subjects had the physical ability to apply the study preparations correctly and to follow the study restrictions and visits. Each patient had at least 3 but not more than 8 clinically confirmed AK target lesions. The lesions were clinically typical, visible and discrete AKs on the face, scalp, trunk and extremities.

Patient exclusion criteria-Excluded from the study were patients 1) who were pregnant or lactating; 2) with known sensitivity or allergy to the active medication; 3 ) being immune suppressed; and 4) who had used 5FU or topical treatments within the preceding 2 months; 5) who had active chemical dependency or alcoholism; and 6) who had atrophic, hypertrophic, pigmented, hyperkeratotic lesions or cutaneous horns.

Post-treatment follow-up-Successfully treated patients were followed-up at 6 months and 12 months. Failures

Table 1. Demographics.

\begin{tabular}{ccc}
\hline \multirow{2}{*}{ Characteristic } & \multicolumn{2}{c}{ Treatment group } \\
\cline { 2 - 3 } & Curaderm $^{\text {BEC5 }} \mathbf{n}=\mathbf{3 9}$ & Vehicle $\mathbf{n}=\mathbf{3 9}$ \\
\hline Age (in years): mean & 65.8 & 68.2 \\
Sex: Male & 20 & 20 \\
Sex: Female & 19 & 19 \\
Race: Caucasian & 39 & 39 \\
$\begin{array}{c}\text { Fitzpatrick skin types I, II } \\
\text { and III }\end{array}$ & & \\
\hline
\end{tabular}

were withdrawn and treated by alternative methods.

Statistical analysis - A total of 78 patients (39 in the active group and 39 in the vehicle group) were enrolled in this study. The subjects had 3 to 8 clinically typical, visible, discrete AK lesions. The primary efficacy endpoint was assessed as healing at Day 56 of test lesion, established by clinical evaluation upon completion of the 3 -day treatment. Complete clearance rate was defined as the proportion of subjects or lesions with no (zero) clinically visible AK lesions at the treatment sites. The secondary efficacy end points were global evaluation of response to treatment, assessment of local irritation, and cosmetic outcome as evaluated by an assessment of scarring during the follow-up (categorized as none, mild, moderate, severe). The safety endpoint was assessment of the frequency, nature, and severity of adverse events.

The intention-to-treat (ITT) population was used to assess the primary and secondary efficacy endpoints. The ITT population included all patients who received study medication. The primary and secondary efficacy variables were analyzed by the Cochran-Mantel-Haenszel test (CMH test).

\section{Results}

Figure 2 shows a flow diagram of the participants. In the Curaderm $^{\mathrm{BEC} 5}$ group 38 of 39 patients $(97.4 \%)$ and in the vehicle group 37 of 39 patients $(94.8 \%)$ adhered to the 3 -day dosing regimen. One patient of the Curaderm ${ }^{\mathrm{BEC} 5}$

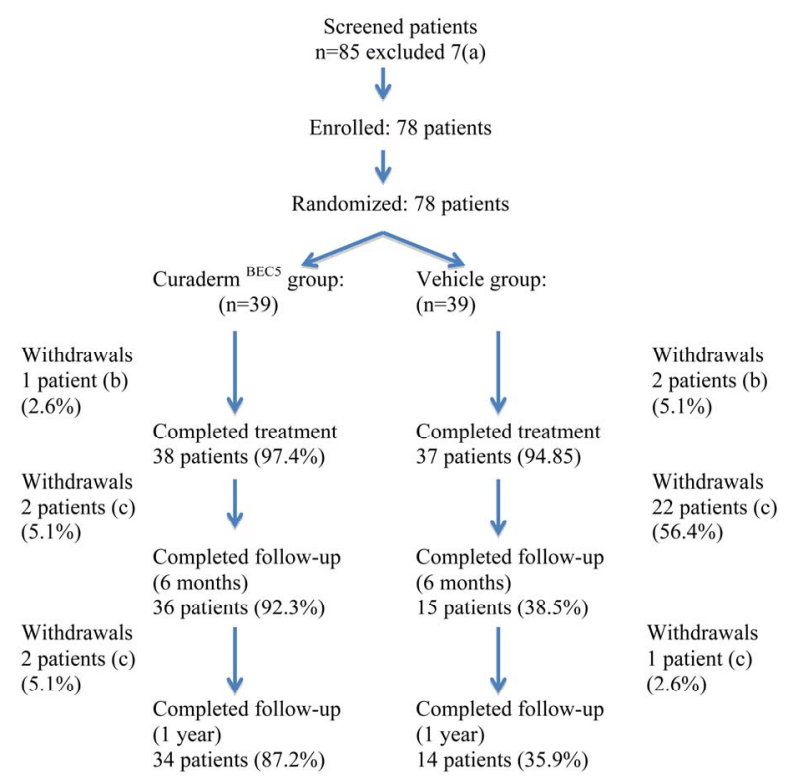

Figure 2. Results flow of participants. Notes: (a) these patients had either atrophic, hypertrophic or hyperkeratotic lesions; (b) 1 patient of the Curaderm ${ }^{\mathrm{BEC} 5}$ group and 2 patients of the vehicle group experienced burning sensations at application sites; (c) on clinical examination these patients were diagnosed with the presence of AK. 
group and 2 patients of the vehicle group experienced burning sensations at application sites after the second dose was administered and withdrew from the study.

Table 2 shows that there were statistically significant differences in efficacy of Curaderm ${ }^{\mathrm{BEC} 5}$ and vehicle groups $(\mathrm{P}<0.001)$ as assessed clinically at 8 weeks, 6 months and 1 year after the 3 days treatment period $(89 \%$ at 8 weeks and $93 \%$ at 1 year for Curaderm ${ }^{\mathrm{BEC} 5}$ as compared to $35 \%$ at 8 weeks and $30 \%$ at 1 year for vehicle). The recurrence rates in the vehicle group were higher on follow-up after 6 months and 1 year. The recurrences in the Curaderm $^{\mathrm{BEC} 5}$ group were much lower than the vehicle group. The absolute success rates, defined as the total number of patient population and number of $\mathrm{AK}$ who were clinically symptom-free after 1 year relative to the number of population and AK on commencement of trial, were $82 \%$ (population) and $78 \%$ (AK lesions) for the Curaderm ${ }^{\mathrm{BEC} 5}$ treatment group. For the vehicle group the absolute success rates were $18 \%$ (population) and $10 \%$ (AK lesions).

There were no SAEs related to Curaderm ${ }^{\mathrm{BEC} 5}$ or vehicle.

The observed adverse events were similar in both the Curaderm ${ }^{\mathrm{BEC} 5}$ and vehicle groups (Table 3 ).

Table 2. Intention-to-treat population statistics.

\begin{tabular}{|c|c|c|c|}
\hline & & $\begin{array}{c}\text { Curaderm Ratio } \\
\text { (\%) }\end{array}$ & $\begin{array}{c}\text { Vehicle Ratio } \\
\text { (\%) }\end{array}$ \\
\hline & Population & $39(100)$ & $39(100)$ \\
\hline & AK lesions & $158(100)$ & $143(100)$ \\
\hline \multirow{2}{*}{$\begin{array}{c}\text { Completed } \\
\text { treatment } \\
\text { (3 days) }\end{array}$} & Population & $38 / 39$ (97) & $37 / 39(95)$ \\
\hline & AK lesions & $154 / 158$ (97) & $140 / 143(98)$ \\
\hline \multirow{2}{*}{$\begin{array}{c}\text { Treatment } \\
\text { success ( } 8 \text { weeks } \\
\text { after treatment })\end{array}$} & Population & $36 / 39(92)$ & $15 / 39(38)$ \\
\hline & AK lesions & 140/158 (89) & $50 / 143(35)$ \\
\hline \multirow{2}{*}{ Treatment failure } & Population & $3 / 39(8)$ & $24 / 39(62)$ \\
\hline & AK lesions & 18/158 (11) & $93 / 143(65)$ \\
\hline \multirow{2}{*}{$\begin{array}{l}\text { Number with } \\
\text { follow-up }\end{array}$} & Population & $34 / 36(94)$ & $14 / 15(93)$ \\
\hline & AK lesions & $133 / 140(95)$ & $46 / 50(92)$ \\
\hline \multirow{2}{*}{$\begin{array}{l}\text { Recurrence at } \\
6 \text { months }\end{array}$} & Population & $2 / 34(14)$ & $6 / 14(43)$ \\
\hline & AK lesions & 9/133 (7) & $30 / 46(65)$ \\
\hline \multirow{2}{*}{$\begin{array}{l}\text { Recurrence at } \\
12 \text { months }\end{array}$} & Population & $0 / 32(0)$ & $1 / 18(6)$ \\
\hline & AK lesions & $0 / 124(0)$ & 2/16 (13) \\
\hline \multirow{2}{*}{$\begin{array}{l}\text { Overall } \\
\text { recurrence }\end{array}$} & Population & $2 / 34(6)$ & $7 / 14(50)$ \\
\hline & AK lesions & 9/133 (7) & $32 / 46(70)$ \\
\hline \multirow{2}{*}{ Success at 1 year } & Population & $32 / 34(94)$ & $7 / 14(50)$ \\
\hline & AK lesions & $124 / 133(93)$ & $14 / 46(30)$ \\
\hline
\end{tabular}

Table 3. Local skin reactions in the treatment area at end of treatment ( 3 days, 2 applications per day) and during 56 days post treatment.

\begin{tabular}{ccccc}
\hline Skin reactions & \multicolumn{2}{c}{3 days treatment } & \multicolumn{2}{c}{ 56 days post treatment } \\
\hline & $\begin{array}{c}\text { Curaderm } \\
\text { BEC5 }\end{array}$ & vehicle & $\begin{array}{c}\text { Curaderm } \\
\text { BEC5 }\end{array}$ & vehicle \\
\hline Erythema & $151(97 \%)$ & $140(98 \%)$ & $4(2 \%)$ & $3(2 \%)$ \\
Swelling & $131(83 \%)$ & $121(85 \%)$ & $0(0 \%)$ & $0(0 \%)$ \\
Erosion & $142(90 \%)$ & $126(88 \%)$ & $0(0 \%)$ & $0(0 \%)$ \\
Crusting & $126(80 \%)$ & $119(83 \%)$ & $4(2 \%)$ & $9(6 \%)$ \\
Loss of pigment & $0(0 \%)$ & $0(0 \%)$ & $5(3 \%)$ & $7(5 \%)$ \\
\hline
\end{tabular}

There were no statistical significant differences in the parameters when Curaderm ${ }^{\mathrm{BEC} 5}$ was compared with the vehicle.

Local skin reactions, including erythema, flaking/scaling, pruritus, swelling, crusting, and erosion/ulceration, pigmentation changes and scarring were assessed within the selected treatment area.

Local skin reactions consisting mainly of erythema, scaling, erosion and mild to moderate pain due to Curaderm $^{\mathrm{BEC} 5}$ and vehicle typically occurred 1 day (third application) of treatment initiation, peaked in intensity until completion of treatment (third day, 6 applications), and resolved within 2 weeks. Subjective assessment of the treated lesions for scarring at 6 months and 1 year showed no significant differences between treatment groups.

Figures 3 to 5 show AKs before, during and after therapy with Curaderm ${ }^{\mathrm{BEC} 5}$. It can be seen that during (Day 3, final day of treatment) the lesions were inflamed, with some scaling, crusting and erosion (Figures 3(b) and 4(b)). These skin reactions resolved within 2 weeks (Figures 3(c) and 4(c)). At 56 days after treatment there was no evidence that the successfully treated lesions were once present (Figures 3(d) and 4(d)).

Figure 6 shows two separate AKs, before and 56 days after completion of treatment with Curaderm ${ }^{\mathrm{BEC} 5}$.

A small proportion of patients experienced depigmentation during Curaderm ${ }^{\mathrm{BEC} 5}$ therapy, but this is resolved over a period of time (Figure 7).

\section{Discussion}

AK is very common, affecting half of the global population. Untreated lesions have up to $20 \%$ risk of progression to squamous cell carcinoma that in turn has $2 \%-6 \%$ risk of metastasizing with the potential of fatality. So treatment of AK is recommended.

The type of treatment of AK depends on size, location and number of lesions present as well as individual patient characteristics.

If only a small number of $\mathrm{AK}$ is to be treated, treat- 


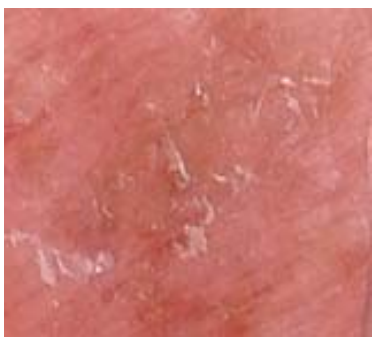

(a)

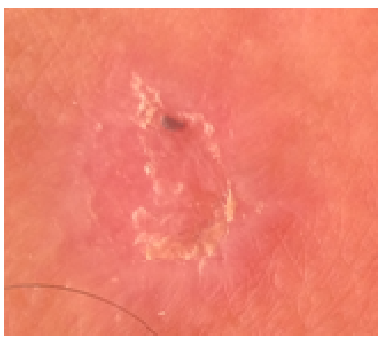

(c)

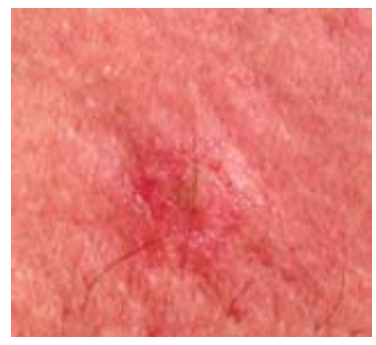

(b)

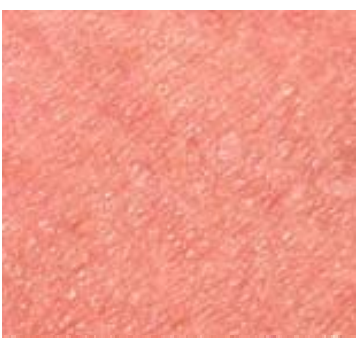

(d)
Figure 3. AK before Curaderm ${ }^{\text {BEC5 }}$ therapy (a); some erosion can be seen at completion of 3 days treatment (b); minor crusting is present 2 weeks after completion of treatment (c); no residual lesion present 56 days after treatment (d). The total Curaderm ${ }^{\mathrm{BEC} 5}$ treatment period was 3 days with 6 applications only.

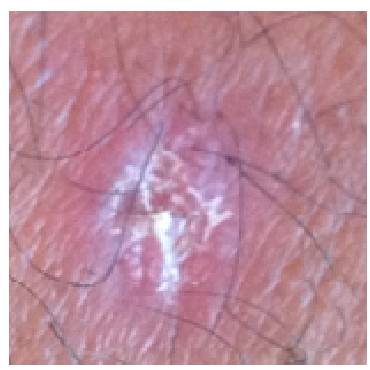

(a)

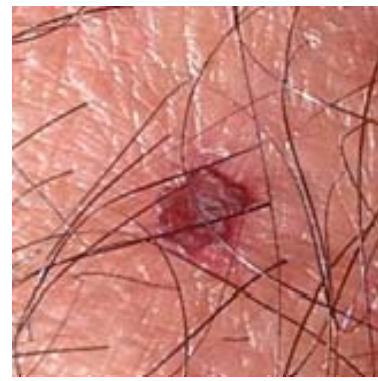

(c)

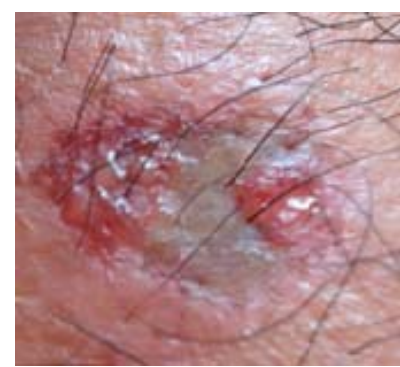

(b)

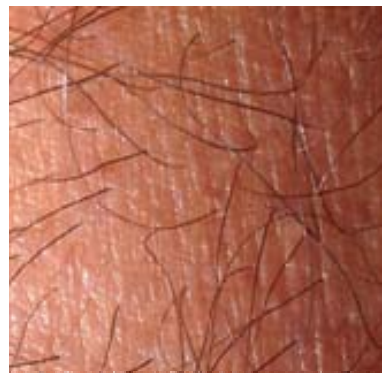

(d)
Figure 4. AK before Curaderm ${ }^{\mathrm{BEC} 5}$ therapy (a); significant erosion and ulceration are seen at completion of 3 days treatment (b); healing of treated lesion with minor crusting is seen 2 weeks after completion of treatment (c); no residual lesion present 56 days after treatment, it is not possible to distinguish where the lesion was before treatment (d). The total Curaderm ${ }^{\mathrm{BEC} 5}$ treatment period was 3 days with 6 applications only.

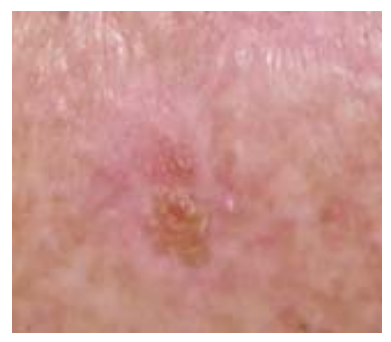

(a)

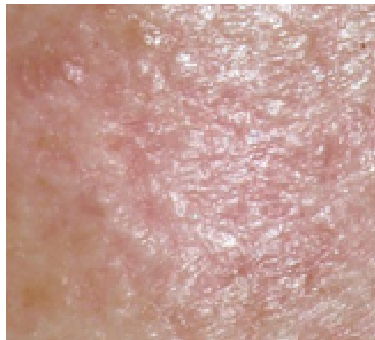

(c)

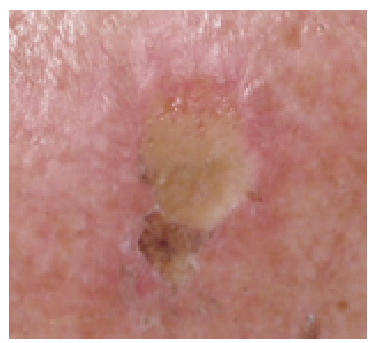

(b)

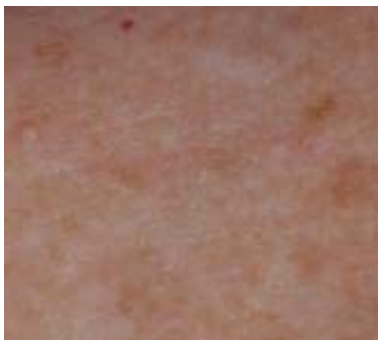

(d)
Figure 5. AK before Curaderm ${ }^{\mathrm{BEC} 5}$ therapy (a); significant erosion and ulceration are seen at completion of 3 days treatment (b); healing of treated lesion is seen 2 weeks after completion of treatment (c); no residual lesion present 56 days after treatment, it is not possible to distinguish where the lesion was before treatment (d). The total Curaderm ${ }^{\text {BEC5 }}$ treatment period was 3 days with 6 applications only.

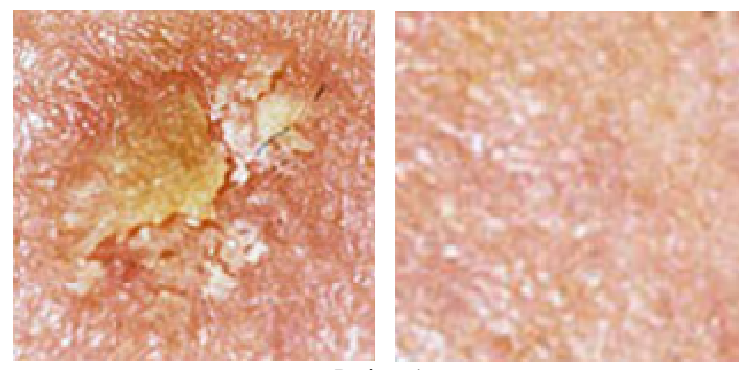

Patient 1

(a)

(b)

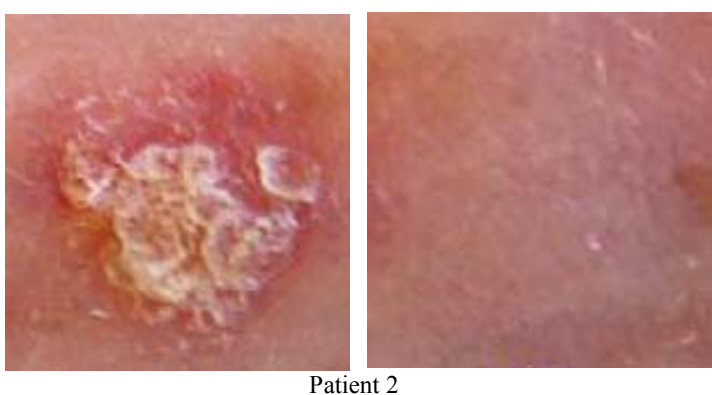

(c)

(d)

Figure 6. Two AKs before Curaderm ${ }^{\mathrm{BEC} 5}$ therapy (a); and 56 days after 3 days of treatment (b).

ment is focused on physically removing individual lesions by cryotherapy, curettage or shave excision. How- 
ever, some of the disadvantages of these methods include moderate pain, discomfort, scarring, and need of local anaesthetic, infection, abnormal pigmentation and recurrence.

For more widespread AK, topical therapies are available such as 5-FU, imiquimod, diclofenac and photodynamic therapy (PDT). Some disadvantages of topical therapies are discomfort, burning, itch, redness, crusting, ulceration, erosion, weeping, flaking, vesicle formation, intolerable pain, and recurrence of the treated lesions and long duration of therapy. In particular, formulations of imiquimod must be applied for periods of weeks to months, fluorouracil for weeks, and diclofenac for months. In addition to the drawbacks of long duration of treatments and consequently prolonged local reactions, which lead to less-than-ideal adherence to therapy, one has to address the success rates. For example, 3\% diclofenac gel treatment for 60 days results in 33\% success rates; those who received placebo had success rates of $10 \%$ [40]. Three months treatment resulted in a higher success rate of $50 \%$, so did the placebo, which had a $20 \%$ success rate [41]. Similarly, treatment with various imiquimod formulations for up to 16 weeks resulted in clearances of $30.6 \%$ to $45.1 \%[42,43]$. Fluorouracil cream applied for 1 to 4 weeks resulted in clearances of $\mathrm{AK}$ ranging from $19.5 \%$ to $47.5 \%[44,45]$.

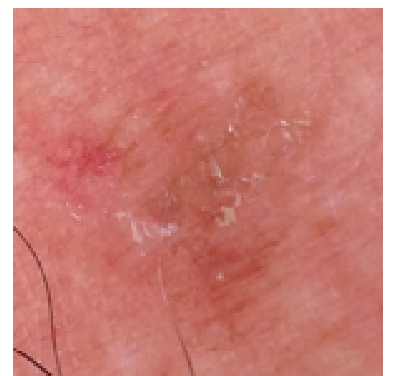

(a)

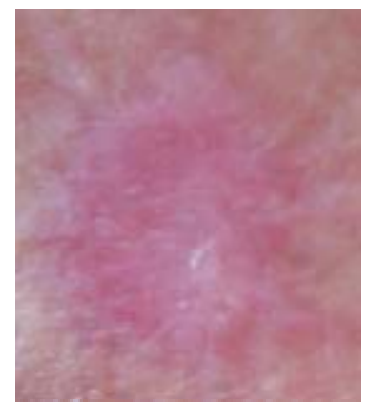

(c)

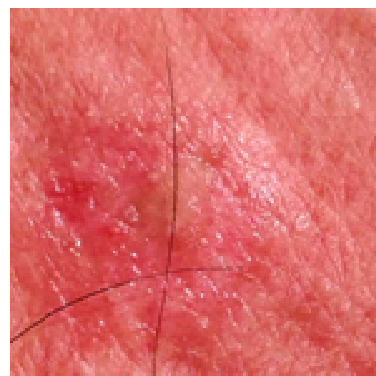

(b)

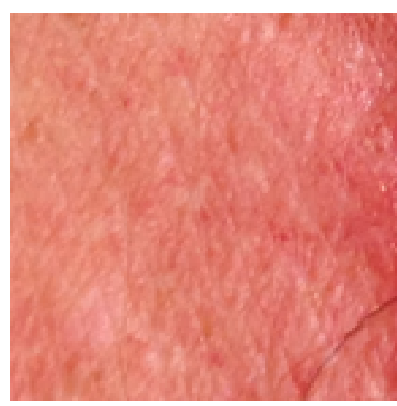

(d)
Figure 7. An AK on the chest of a patient before (a); at completion of 3 days treatment (b); 56 days after treatment (c); and 6 months after completion of treatment (d); A depigmented area is seen 56 days after treatment. Treatment area has regained normal pigmentation after 6 months.
Recently a new topical gel containing ingenol mebutate has been reported for the treatment of AK. This topical gel shows the same disadvantages as described for other topical treatments. Reports on ingenol mebutate indicate that the treatment period for $\mathrm{AK}$ is much less than other topical treatments. However, the success rates are not much better and are in the same range as other topical treatments. The absolute efficacy of ingenol mebutate with the follow-up period of 1 year is $21 \%-25 \%$ [46]. It is interesting to note that in the current study the absolute efficacy with a follow-up period of 1 year for the vehicle group is $18 \%$. In a previous clinical trial it was shown that the same vehicle used in the current study had a therapeutic effect on basal cell carcinoma. The keratolytic agents salicylic acid and urea appear to have a beneficial effect on AK and basal cell carcinoma. A similar cream formulation but without BEC, salicylic acid and urea has no therapeutic effect on AK (unpublished observations). However, as shown in this study and the clinical trial with basal cell carcinoma, the therapeutic effect of the BEC glycoalkaloids in Curaderm ${ }^{\mathrm{BEC} 5}$ is statistically significant when compared to the placebo effect of salicylic acid and urea $(\mathrm{p}<0.001)$.

In other studies with longer duration treatment periods it was shown that Curaderm ${ }^{\mathrm{BEC} 5}$ is effective for the treatments of keratosis, basal cell carcinoma and squamous cell carcinoma [4,29,32-36,38]. It was recently reported that SR-T100 extracted from S. incanum containing solamargine as the main active ingredient induced apoptosis in squamous cell carcinoma in vitro and in vivo. SR-T100 induced the expression of tumour necrosis factor receptors (TNFRs) and Fas. SR-T100 also triggered the mitochondrial apoptotic pathway by up-regulating cytochrome $\mathrm{c}$ and Bax and down-regulating Bcl-xL. These observations confirm the mode of action of solasodine glycosides as previously described $[8,22,23,27-31,38,39]$. SR-T100 was effective against micro invasive squamous cell carcinoma in hairless mice and $\mathrm{AK}$ in human patients. The treatment for AK was for 16 weeks and there were negligible discomforts [47].

A successful topical treatment for $\mathrm{AK}$ in the clinical setting dictates that the treatment should be effective, safe and convenient to use. Now, for the first time, it is shown that 6 applications of Curaderm ${ }^{\mathrm{BEC} 5}$ over a 3-day period results in the clearance of over $80 \%$ of AKs.

The $35 \%$ success rate for the vehicle group may be explained by the presence of the effective keratolytic agents salicylic acid and urea in the composition resulting in the clearance of some AK. An identical placebo used in Curaderm ${ }^{\mathrm{BEC} 5}$ clinical trials of basal cell carcinoma also resulted in high (25\%) success rates [34].

Less than 1 milliliter of the solasodine glycoside cream is adequate to clear an AK lesion. This is an important 
issue, since it has been reported that skin cancer is among the most costly of all cancers to treat for the USA Medicare population. In light of the already high and rising incidences, the cost of keratosis and non-melanoma skin cancer care to Medicare is likely to increase. Thus, it is essential to preserve low per-patient costs of their management [48]. The relative rapid resolution of local reactions and the short duration of treatment period lead to very high adherence to Curaderm ${ }^{\mathrm{BEC} 5}$ therapy. This is in stark contrast to most other treatment modalities.

Interaction and internalization of BEC with a specific rhamnose binding receptor protein identified on cancer cells trigger extrinsic and intrinsic apoptotic pathways resulting in apoptosis of the affected cells. Specificity is the key factor of BEC. It was previously reported that regeneration of new epidermis at the application site of Curaderm $^{\mathrm{BEC} 5}$, despite continued application of Curaderm ${ }^{\mathrm{BEC} 5}$, occurred when treating basal cell carcinoma [34] and squamous cell carcinoma [36]. Preclinical [4,8,22,23,27-31,38] and clinical $[4,20-22,29,32-36]$ observations support that BEC preferentially acts in the lysis of transformed cells by apoptosis as opposed to normal cells which remain unaffected. This may explain the remarkably good cosmetic outcome of Curaderm ${ }^{\mathrm{BEC} 5}$ in the current study with AK and previous studies with basal cell and squamous cell carcinoma [4,20-22,29,32-36]. It is currently unknown whether the immunological effects of solasodine glycosides [25] play a role in the treatment of cutaneous lesions.

Previous studies with Curaderm ${ }^{\mathrm{BEC} 5}$ and other similar formulations containing very high concentrations of BEC for the treatments of non melanoma skin cancers in which the treatment periods were for several months showed that there were no systemic side effects. Extensive laboratory blood tests and urine tests were done in those studies $[32,34,36]$. Such tests showed no systemic adverse effects. The treatment period in this current study was for only 3 days. Therefore, in the current study no laboratory blood tests were performed.

A shortcoming of this study is that it is a singleblinded study. Nevertheless, clinical observations showed that both Curaderm ${ }^{\mathrm{BEC} 5}$ and the vehicle expressed similar skin reactions.

This current study confirms that Curaderm ${ }^{\mathrm{BEC} 5}$ has overall efficacy, patient acceptance and low incidence of local adverse events. It appears that the transformed cells constituting AK may possess the rhamnose binding protein receptor. The local adverse events, which can be considered as a shortcoming, are due to the excipients salicylic acid and urea and not the BEC glycoalkaloids. The main adverse event was mild to moderate pain at the treatment site immediately after application of Curaderm ${ }^{\mathrm{BEC} 5}$ and/or vehicle. This irritation lasted for approximately 15 minutes. Studies are currently underway to establish the effect of a localized topical anaesthetic on Curaderm ${ }^{\mathrm{BEC} 5}$ therapy for AK and other non-melanoma skin cancers.

\section{Conclusions}

In the present study, it is shown that effective clearance of AK with Curaderm ${ }^{\mathrm{BEC} 5}$ compared to vehicle alone is obtained. Three days of treatment with Curaderm ${ }^{\mathrm{BEC} 5}$ is well tolerated with no serious treatment related adverse events. The adverse events that are observed are not due to the BEC glycoalkaloids.

Four clear benefits arise from treatment of AK with Curaderm $^{\mathrm{BEC} 5}$. The first benefit is the relatively very high success rate of over $80 \%$ for Curaderm ${ }^{\mathrm{BEC} 5}$ versus $18 \%$ for the placebo. Secondly, the short duration of treatment resulting in very high $(97 \%)$ adherence to Curaderm ${ }^{\mathrm{BEC} 5}$ therapy is also very acceptable to the patient. Thirdly, Curaderm $^{\mathrm{BEC} 5}$ therapy is relatively inexpensive. Fourthly, the cosmetic outcome after Curaderm ${ }^{\mathrm{BEC} 5}$ therapy is impressive. The BEC glycoalkaloids cream, Curaderm ${ }^{\mathrm{BEC} 5}$, is a safe and effective alternative topical treatment for AKs.

\section{REFERENCES}

[1] E. Stockfleth, C. Ferrandix, J. J. Grob, I. Leigh, H. Pehumberger and H. Kerl, "Development of a Treatment Algorithim for Actinic Keratoses: A European Consensus," European Journal Dermatology, Vol. 18, No. 6, 2008, pp. 651-659.

[2] N. Krawtchenko, J. Roewert-Huber, M. Ulrich, I. Mann, W. Sterry and E. Stockfleth, "A Randomized Study of Topical 5\% Imiquimod vs. Topical 5-Fluorouracil vs. Cryosurgery in Immunocompetent Patients with Actinic Keratoses: A Comparison of Clinical and Histological Outcomes Including 1-Year Follow-Up," British Journal Dermatology, Vol. 157 Supplementary 2, 2007, pp. 34 40.

[3] S. R. Feldman and A. B. Fleishcer Jr., "Progression of Actinic Keratosis to Squamous Cell Carcinoma Revisited: Clinical and Treatment Implications," Cutis, Vol. 84, No. 4, 2011, pp. 201-207.

[4] T. R. Chase, "Curaderm ${ }^{\mathrm{BEC} 5}$ for Skin Cancers, Is It? An Overview," Journal Cancer Therapy, Vol. 2, No. 5, 2011, pp. 728-745. doi:10.4236/jct.2011.25099

[5] B. E. Cham, M. Gilliver and L. Wilson, "Antitumour Effects of Glycoalkaloids Isolated from Solanum sodomaeum L.," Planta Medica, Vol. 53, No. 1, 1987, pp. 34 36. doi:10.1055/s-2006-962612

[6] B. E. Cham and B. Daunter, "Solasodine Glycosides. Selective Cytotoxicity for Cancer Cells and Inhibition of Cytotoxicity by Rhamnose in Mice with Sarcoma 180," Cancer Letters, Vol. 55, No. 3, 1990, pp. 221-225. doi:10.1016/0304-3835(90)90122-E

[7] M. Freedman, K. R. Lee, H. J. Kim, I. S. Lee and N. Ko- 
zukue, "Anticarcinogenic Effects of Glycoalkaloids from Potatoes Against Human Cervical, Liver, Lymphoma and Stomach Cancer Cells," Journal Agriculture Food Chemistry, Vol. 53, No. 15, 2005, pp. 6162-6169. doi:10.1021/jf050620p

[8] K. W. Kuo, S. H. Hsu, Y. P. Li, W. L. Lin, L. F. Liu, L. C. Chang, C. C. Lin, C. N. Lin and H. M. Sheu, "Anticancer Activity Evaluation of the Solanum Glycoalkaloid Solamargine. Triggering Apoptosis in Human Hepatoma Cells," Biochemical Pharmacology, Vol. 60, No. 2, 2000, pp. 8651873. doi:10.1016/S0006-2952(00)00506-2

[9] K. W. Kuo and C. N. Lin, "Pharmacological Composition for Treating Cancer Cells," US Patent: 214,803, 1999.

[10] K. R. Lee, N. Kozukue, J. S. Han, J. H. Park, E. Y. Chang, E. J. Back, J. D. Chang and M. Friedman, "Glycoalkaloids and Metabolites Inhibit the Growth of Human Colon (HT29) and Liver (HepG2) Cancer Cells," Journal Agriculture Food Chemistry, Vol. 52, No. 10, 2004, pp. 28322839. doi:10.1021/jf030526d

[11] C. H. Liang, L. F. Liu, L. Y. Shiu, Y. S. Huang, L. C. Chang and K. W. Kuo, "Action of Solamargine on TNFs and Cisplatin-Resistant Human Lung Cancer Cells," Biochemical Biophysical Research Communication, Vol. 322, No. 3, 2004, pp. 751-758. doi:10.1016/j.bbrc.2004.07.183

[12] C. H. Liang, L. Y. Shiu, L. C. Chang, H. M. Sheu and K. W. Kuo, "Solamargine Upregulation of Fas, Downregulation of HER 2, and Enhancement of Cytotoxicity Using Epirubicin in NSCLC Cells," Molecular Nutrition Food Research, Vol. 51, No. 8, 2007, pp. 999-1005. doi:10.1002/mnfr.200700044

[13] L. F. Liu, C. H. Liang, L. Y. Shiu, W. L. Lin, C. C. Lin and K. W. Kuo, "Action of Solamargine on Human Lung Cancer Cells-Enhancement of the Susceptibility of Cancer Cells to TNFs," FEBS Letters, Vol. 577, No. 1-2, 2004, pp. 67-74. doi:10.1016/j.febslet.2004.09.064

[14] M. Millward, A. Powell, P. Daly, S. Tyson, R. Ferguson and S. Carter, "Results of Phase I Clinical Trials of Coramsine in Patients with Advanced Solid Tumors," Journal Clinical Oncology, Vol. 2, No. 18, 2006, p. 2070.

[15] T. Nakamura, C. Komori, Y. Lee, F. Hashinoto, S. Yahara, T. Nohara and A. Ejina, "Cytotoxic Activities of Solanum Steroidal Glycosides," Biology Biopharmacy Bulletin, Vol. 19, No. 4, 1996, pp. 564-566. doi:10.1248/bpb.19.564

[16] K. Ono, S. O. Kin and J. Han, "Susceptibility of Lysosomes to Rupture Is a Determinant for Plasma Membrane Disruption in Tumor Necrosis Factor Alpha-Indued Cell Death," Molecular Cell Biology, Vol. 23, No. 2, 2003, pp. 665-676. doi:10.1128/MCB.23.2.665-676.2003

[17] M. Ono, K. Nishimura, K. Suzuki, T. Fukushima, K. Igoshi, H. Yoshimitsu, T. Ikeda and T. Nohara, "Steroidal Glycosides from the Underground Parts of Solanum Sodomaeum," Chemical Pharmacy Bulletin, Vol. 54, No. 2, 2006, pp. 230-233. doi:10.1248/cpb.54.230

[18] J. G. Roddick, A. L. Rÿrenber and M. Weissenber, "Membrane-Disrupting Properties of the Steroidal Glycoalkaloids Solasonine and Solamargine," Phyto Chemistry, Vol.
29, No. 5, 1990, pp. 1513-1518. doi:10.1016/0031-9422(90)80111-S

[19] P. Vijayan, K. S. Vinod, S. A. Dhanaraj, S. Badami and B. Suresh, "In Vitro Cytotoxicity and Anti-Tumour Properties of the Total Alkaloid Fraction of Unripe Fruits of Solanum Pseudocapsicum," Pharmacology Biology, Vol. 40, No. 6, 2002, pp. 456-460. doi:10.1076/phbi.40.6.456.8444

[20] B. E. Cham, "Solasodine Rhamnosyl Glycosides Specifically Bind Cancer Cell Receptors and Induce Apoptosis and Necrosis. Treatment for Skin Cancer and Hope for Internal Cancers," Research Journal Biological Science, Vol. 2, No. 7, 2007, pp. 503-514.

[21] B. E. Cham, "Solasodine Rhamnosyl Glycosides in a Cream Formulation Is Effective for Treating Large and Troublesome Skin Cancers," Research Journal Biological Science, Vol. 2, No. 7, 2007, pp. 749-761.

[22] B. E. Cham, "Cancer Intralesion Chemotherapy with Solasodine Rhamnosyl Glycosides," Research Journal Biological Science, Vol. 3, No. 9, 2008, pp. 1008-1017.

[23] L. Y. Shiu, L. C. Chang, C. H. Liang, Y. S. Huang, H. M. Sheu and K. W. Kuo, "Solamargine Induces Apoptosis and Sensitizes Breast Cancer Cells to Cisplatin," Food Chemical Toxicology, Vol. 45, No. 11, 2007, pp. 21552164. doi:10.1016/j.fct.2007.05.009

[24] Google Search, "Solamargine Anticancer,"

[25] B. E. Cham and T. R. Chase, "Solasodine Rhamnosyl Glycosides Cause Apoptosis in Cancer Cells, Do They Also Prime the Immune System Resulting in Long Term Protection against Cancer?" Planta Medica, Vol. 78, 2012, pp. 349-353. doi:10.1055/s-0031-1298149

[26] R. G. Van der Most, R. Himbeck, S. Aarens, S. J. Carter, I. Larma, C. Robinson, A. Currice and R. A. Lake, "Antitumor Efficacy of the Novel Chemotherapeutic Agent Coramsine Is Potentiated by Cotreatment with CpG-Containing Oligodeoxynucleotides," Journal Immunology, Vol. 29, No. 2, 2006, pp. 134-142.

[27] B. Daunter and B. E. Cham, "Solasodine Glycosides. In Vitro Preferential Cytotoxicity for Human Cancer Cells," Cancer Letters, Vol. 55, No. 3, 1990, pp. 209-220. doi:10.1016/0304-3835(90)90121-D

[28] X. Li, Y. Zhao, W. K. K. Wu, S. Liu, M. Cui and H. Lou, "Solamargine Induces Apoptosis Associated with p53 Transcription-Dependent and Transcription-Independent Pathways in Human Osteosarcoma U20S Cells," Life Science, Vol. 88, No. 7-8, 2011, pp. 314-321. doi:10.1016/j.lfs.2010.12.006

[29] B. E. Cham, "Solasodine Glycosides as Anti-Cancer Agents: Pre-Clinical and Clinical Studies," Asia Pacific Journal Pharmacology, Vol. 9, No. 2, 1994, pp. 113-118.

[30] L. Y. Shiu, C. H. Liang, Y. S. Huang, H. M. Sheu and K. W. Kuo, "Downregulation of HER2/neu Receptor by Solamargine Enhances Anticancer Drug-Mediated Cytotoxicity in Breast Cancer Cells with High-Expressing HER2/ neu," Cell Biology Toxicology, Vol. 24, No. 1, 2008, pp. 110.

[31] L. Sun, Y. Zhao, H. Yuan, X. Li, A. Cheng and H. Lou, 
"Solamargine, a Steroidal Alkaloid Glycoside, Induces On- cosis in Human K562 Leukemia and Squamous Cell Car- cinoma KB Cells," Cancer Chemotherapy Pharmacology, Vol. 65, No. 4, 2010, pp. 1125-1130. doi:10.1007/s10565-007-9010-5

[32] B. E. Cham, B. Daunter and R. Evans, "Topical Treatment of Malignant and Premalignant Skin Cancers by Very Low Concentrations of a Standard Mixture of Solasodine Glycosides," Cancer Letters, Vol. 59, No. 3, 1991, pp. 183-192. doi:10.1016/0304-3835(91)90140-D

[33] B. E. Cham and H. M. Meares, "Glycoalkaloids from Solanum Sodomaeum L. Are Effective in the Treatment of Skin Cancers in Man," Cancer Letters, Vol. 36, No. 2, 1987, pp. 111-118. doi:10.1016/0304-3835(87)90081-4

[34] S. Punjabi, L. J. Cook, P. Kersey, R. Marks and R. Cerio, "Solasodine Glycoalkaloids: A Novel Topical Therapy for Basal Cell Carcinoma. A Double-Blind, Randomized, Placebo-Controlled, Parallel Group, Multicentre Study," International Journal Dermatology, Vol. 47, No. 1, 2008, pp. 78-82. doi:10.1111/j.1365-4632.2007.03363.x

[35] B. E. Cham, "Topical Solasodine Rhamnosyl Glycosides Derived from the Eggplant Treats Large Skin Cancers: Two Case Reports," International Journal Clinical Medicine, Vol. 2, No. 4, 2011, pp. 473-477.

[36] L. H. Goldberg, J. M. Landau, M. N. Moody and I. J. Vergilis-Kalner, "Treatment of Bowen's Disease on the Penis with Low Concentration of a Standard Mixture of Solasodine Glycosides and Liquid Nitrogen," Derma- tologic Surgery, Vol. 37, No. 6, 2011, pp. 858-861. doi:10.1111/j.1524-4725.2011.02014.x

[37] B. E. Cham and L.Wilson, "HPLC of Glycoalkaloids from Solanum Sodomaeum," Planta Medica, Vol. 53, No. 1, 1987, pp. 34-36. doi:10.1055/s-2006-962612

[38] B. E. Cham, "Intralesion and Curaderm ${ }^{\mathrm{BEC} 5}$ Topical Combination Therapies of Solasodine Rhamnosyl Glycosides Derived from the Eggplant or Devil's Apple Result in Rapid Removal of Large Skin Cancers. Methods of Treatment Compared," International Journal Clinical Medicine, Vol. 3, No. 2, 2012, pp. 115-124. doi:10.4236/ijcm.2012.32024

[39] B. E. Cham, "Drug Therapy: Solamargine and Other Solasodine Rhamnosyl Glycosides as Anticancer Agents," Modern Chemotherapy, in Press.

[40] J. K. Rivers, J. Arlette, N. Shear, L. Guenther, N. Carey and Y. Poulin, "Topical Treatment of Actinic Keratoses with $3.0 \%$ Diclofenac in $2.5 \%$ Hyaluran Gel," British
Journal Dermatology, Vol. 146, No. 1, 2002, pp. 94-100. doi:10.1046/j.1365-2133.2002.04561.x

[41] J. E. Wolf Jr., J. R. Taylor, E. Tschen and S. Kang, "Topical 3.0\% Diclofenac in 2.5\% Hyaluran Gel in the Treatment of Actinic Keratoses," International Journal Dermatology, Vol. 40, No. 11, 2001, pp. 709-713. doi:10.1046/j.1365-4362.2001.01324.x

[42] M. Lebwohl, S. Dinehart, D. Whiting, et al., "Imiquimod 5\% Cream for the Treatment of Actinic Keratosis: Results from Two Phase III, Randomized, Double-Blind Parallel Group, Vehicle Controlled Trials," Journal American Academy Dermatology, Vol. 50, No. 5, 2004, pp. 714-721. doi:10.1016/j.jaad.2003.12.010

[43] N. Swanson, W. Abramovits, B. Breman, J. Kulp, D. S. Rigel and S. Levy, "Imiquimod $2.5 \%$ and $3.75 \%$ for the Treatment of Actinic Keratoses: Results of Two Pla- cebo-Controlled Studies of Daily Application to the Face and Balding Scalp for Two 2-Week Cycles," Journal American Academy Dermatology, Vol. 62, No. 4, 2010, pp. 582-590. doi:10.1016/j.jaad.2009.07.004

[44] J. Weiss, A. Menter, O. Hevia, et al., "Effective Treatment of Actinic Keratosis with $0.5 \%$ Fluorouracil Cream for 1, 2 or 4 Weeks," Cutis, Vol. 70, Suppl. 2, 2002, pp. 22-29.

[45] B. Yentzer, J. Hick, L. Williams, et al., "Adherence to a Topical Regimen of 5-Fluorouracil, 0.5\% Cream for the Treatment of Actinic Keratoses," Academy Dermatology, Vol. 145, No. 2, 2009, pp. 203-205.

[46] "Highlights of Prescribing Information-Picato Gel," 2012. www.leo-pharma.us/Files/Billeder/LEO_local_images/LE O-Pharma.US/Releases/Picato\%20PI.pdf

[47] C. H. Wu, C. H. Liang, L. Y. Shiu, L. C. Chang, T. S. Lin, C. E. R. Lan, J. C. Tsai, T. W. Wong, K. J. Wei, T. K. Lin, N. S. Chang and H. M. Sheu, "Solanum Incanum Extract (SR-T100) Induces Human Cutaneous Squamous Cell Carcinoma Apoptosis through Modulating Tumor Necrosis Factor Receptor Signaling Pathway," Journal Dermatology Science, Vol. 63, No. 2, 2011, pp. 83-92.

[48] T. M. Housman, S. R. Feldman, P. M. Williford, A. B. Fleischer Jr., N.D. Goldman, M. Acostamadiedo and G. J. Chen, "Skin Cancer Is Among the Most Costly of All Cancers to Treat for the Medicare Population," Journal American Academy Dermatology, Vol. 48, No. 3, 2003, pp. 425-429. doi:10.1067/mjd.2003.186 